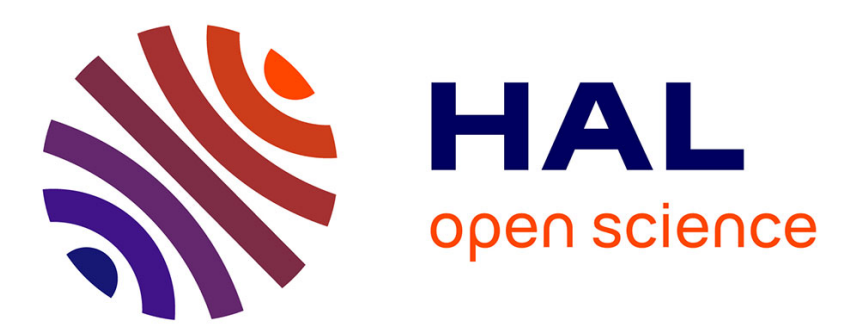

\title{
Sugar beet pectins: chemical structure and gelation through oxidative coupling
}

F.M. Rombouts, J.F. Thibault

\section{To cite this version:}

F.M. Rombouts, J.F. Thibault. Sugar beet pectins : chemical structure and gelation through oxidative coupling. American Chemical Society symposium, 1986, Washington, United States. hal-02783910

\section{HAL Id: hal-02783910 \\ https://hal.inrae.fr/hal-02783910}

Submitted on 4 Jun 2020

HAL is a multi-disciplinary open access archive for the deposit and dissemination of scientific research documents, whether they are published or not. The documents may come from teaching and research institutions in France or abroad, or from public or private research centers.
L'archive ouverte pluridisciplinaire HAL, est destinée au dépôt et à la diffusion de documents scientifiques de niveau recherche, publiés ou non, émanant des établissements d'enseignement et de recherche français ou étrangers, des laboratoires publics ou privés. 
acetylester groups mainly, and further to the relatively small size of the beet pectin molecules (2).

our recent studies on sugar-beet pectins have revealed some new features, which may increase their usefulness, and possibly lead to some new applications.

\section{Experimental methods}

Materials. Pressed sugar-beet pulp, preserved in four volumes of ethanol was obtained from a sugar factory at Eppeville, France. Endopolygalacturonase was purified from a preparation from Aspergildopolygalacturonase was purified
lus niger, as described by Thibault and Mercier (3). Endopectate
lyase was obtained from Pseudomonas fluorescens (4). Endopectin lyase (type 2) was isolated from a preparation of A. niger (5). Pectinesterase was purified from an $A$. niger preparation according to Baron et al (6). Exo $\alpha(1 \rightarrow 5)$ arabinanase and endo $\beta(1-4)$ galactanase were also purified from A. niger (unpublished results). Horse radish peroxidase $(90 \mathrm{U} / \mathrm{mg}$ solid) was obtained from Sigma Chem. Comp., St. Louis, Mo. USA.

Extraction and purification. An alcohol-insoluble residue was prepectin (OXP), acid-soluble pectin (IIP) and alkali-soluble pectin (OHP). Extractions were done according to the procedure described by Barbier and Thibault (7). The pectins were purified by chromatography at $\mathrm{pH} 4.8$ on Whatman DEAE-cellulose DE 52 under the conditions described by Barbier and Thibault (7). As the alkali-soluble pectin binds irreversibly to this column, this fraction was purified by precipitation with $\mathrm{CuSO}_{4}$ and extensive washing of the precipitate. Cupric ions were subsequently removed by dialysis against $\mathrm{Na}_{2}$ EDTA at $\mathrm{pH} 4.8$.

Analytical methods. The anhydrogalacturonic acid content and neutral sugar content (expressed as anhydro-arabinose) of pectins were determined automatically by the m-hydroxydiphenyl method ( 8 ) and the orcinol method (9) respectively. In the latter method corrections were made for interference from anhydrogalacturonic acid. Neutral sugar residues in pectins were determined by gas-liquid chromatography of the alditolacetates (10) prepared from the sugars after hydrolysis with $2 \mathrm{M}$ trifluoro-acetic acid during $1.5 \mathrm{~h}$ at $120^{\circ} \mathrm{C}$. Methylester groups were determined according to Wood and Siddiqui (11). 0-acetyl groups were liberated from pectins by hydrolysis with $0.1 \mathrm{M}$ sodium hydroxide for $1 \mathrm{~h}$ at room temperature. After neutralisation, acetic acid was determined by gas-liquid chromatography with formic acid-saturated nitrogen as carrier gas (12). Feruloylester groups were estimated spectrophotometrically at $375 \mathrm{~nm}$, using freshly prepared pectin solutions in $0.1 \mathrm{M}$ glycinesodium hydroxide buffer, pH 10 . The feruloylester content was calculated using a molar extinction coefficient of 31600 (13). Polyphenols were estimated with the Folin-Ciocalteu reagent without copper treatment (14), using ferulic acid as standard. Intrinsic. viscosities and viscosity-average molecular weights of pectins were determined with the method of Owens et al (15). 
Chromatography. Purified pectins and their degradation products were studied by gel-permeation chromatography on Sepharose CL-2B or Sepharose CL-6B (Pharmacia), under conditions as described by Barbier and Thibault (7). High-performance size exclusion chromatography was done with a series of Biogel TSK columns types 6000 , 5000,4000 and $3000 \mathrm{PW}$ (Bio-Rad Labs., Richmond, Ca., USA). The solvent was $0.1 \mathrm{M}$ sodium sulfate in sodium acetate, pH 3.7 , ionic strength 0.34 (16).

Degradation studies. Degradation limits by endopolygalacturonase and by $\beta$-elimination were determined as described by Thibault (17) and by endopectate lyase as described by Rombouts et al (4). For pectin lyase the reaction conditions were $0.25(\mathrm{w} / \mathrm{v})$ pectin, $0.01 \mathrm{M}$ sodium phosphate buffer, $\mathrm{pH} 5.2$ and $0.52 \mathrm{U} / \mathrm{ml}$ of pectin lyase, $30^{\circ} \mathrm{C}, 24 \mathrm{~h}$. The pectin lyase reaction was monitored by measuring $\mathrm{A}_{235} \mathrm{~nm}$ of aliquots, diluted thirtyfold with $0.1 \mathrm{~N}$ hydrochloric acid and the degradation limit was calculated, using a molar extinction coefficient of 5500 (18).

Alkaline deesterification of pectins was done by dialysis of pectin solutions $(4 \mathrm{mg} / \mathrm{ml})$ against $0.05 \mathrm{~N}$ sodium hydroxide at $2^{\circ} \mathrm{C}$ for $6 \mathrm{~h}$.

Conditions for enzymatic demethylation were $0.4 \%(w / v)$ pectin, $0.1 \mathrm{M}$ sodium acetate buffer, pH 4.5 and $5.7 \mathrm{U} / \mathrm{ml}$ of pectinesterase, $30^{\circ} \mathrm{C}, 24 \mathrm{~h}$. Inactivation of enzymes was done by heating of the reaction mixtures for $5 \mathrm{~min}$ in a boiling water bath. The reaction conditions for exoarabanase and endogalactanase were $0.75 \%(\mathrm{w} / \mathrm{v})$ pectin, $0.05 \mathrm{M}$ sodium phosphate buffer $\mathrm{pH} 6$ and $7 \mathrm{~J} / \mathrm{ml}$ of exoarabanase and $0.66 \mathrm{U} / \mathrm{ml}$ of endogalactanase, $30^{\circ} \mathrm{C}, 24 \mathrm{~h}$. The reactions were monitored by measuring increase in reducing groups with the method of Nelson-Somogyi (19).

Crosslinking and gelation. To sugar-beet pectin solutions of varying concentrations between 0.25 and $3 \%(\mathrm{w} / \mathrm{v})$ in $0.1 \mathrm{M}$ sodium phosphate bufter pH 6.0 were added (per mi of peciil suluituil): in microlitres of peroxidase solution of a concentration of $1 \mathrm{mg}$ of enzyme per $\mathrm{ml}$ and, after mixing, $0.1 \mathrm{ml}$ of $0.1 \mathrm{M}$ hydrogen peroxide solution. At higher pectin concentrations $(\geqq 1.0 \% \mathrm{w} / \mathrm{v})$ gelation occurred immediately upon mixing while at lower pectin concentrations viscosity increased. Pectin gels or solutions with increased viscosity were also obtained by treatment with $0.01 \mathrm{M}$ anmonium persulfate, at $25^{\circ} \mathrm{C}$ for up to $15 \mathrm{~h}$ (measured by reduced specific viscosity).

Results and discussion

The yields of crude pectins, as well as their anhydrogalacturonic acid content are given in Table $I$. This Table shows that about one third of the alcohol-insoluble residue can be solubilised as crude pectins, but the anhydrogalacturonide content of these pectins is very low. Most of the pectins are extracted with acid and subsequently with alkali. Even after these extractions not all of the pectin is solubilised from the alcohol-insoluble residue: its anhydrogalacturonic acid content is still some $5 \%$.

Purification and composition. The purification of these pectins, carried out as described in "Experimental Methods" results in an 
Table I. Pectins extracted from sugar-beet pulp

\begin{tabular}{llll}
\hline Pectin fraction & & Yield & $\begin{array}{l}\text { Anhydrogal. } \\
\text { acid content } \\
(\% \mathrm{w} / \mathrm{w})\end{array}$ \\
\hline Water-soluble & (WSP) & 2.2 & 31 \\
Oxalate-soluble & (OXP) & 0.5 & 50 \\
Acid-soluble & (HP) & 20 & 36 \\
Alkali-soluble & (OHP) & 11 & 41 \\
Pectin extracted & & $\overline{33} .7$ & \\
\hline
\end{tabular}

appreciable increase in anhydrogalacturonic acid content (Table II). Neutral sugar residues present in all four pectins are arabinose and galactose mainly and further rhamnose, fucose, xylose, mannose and glucose. Total neutral sugar content varies from 5.7 to $24.3 \%$, in different pectins which is relatively high when compared to pectins from apple pomace and citrus wastes (20). Degrees of methylation are comparable to those of certain types of comercial pectins (from apples and citrus) which, unlike these pectins, contain few or no acetylester groups. The weight percentage values in Table II do not add up to $100 \%$ as the purified pectins still contain some protein, unbound polyphenols and sodium counterions. Viscosity-average molecular masses are low, as compared to those of pectins from apple, citrus fruits or cherries, which are in the order of 70000 to $90000(20,7)$.

Gel-permeation chromatograms (Figure 1) of purified pectins on Sepharose CL-2B (WSP, HP, OHP) and CL-6B (OXP) show a fairly continuous variation of the distribution of neutral sugars over the pectin molecules of varying molecular mass, except for OHP, which apparently consists of two different populations of molecules: high molecular mass pectin rich in neutral sugars and low molecular mass pectin with a low neutral sugar content. As will be clear from degradation studies, this partition points towards breakdown of the pectin molecules during alkaline extraction.

Table II. Composition and properties of purified pectins from sugar-beet pulp.

\begin{tabular}{lcccc}
\hline & WSP & OXP & HP & \multicolumn{1}{c}{ OHP } \\
\hline Anhydrogalacturonic acid & 54.4 & 77.9 & 65.1 & 54.9 \\
Neutral sugars & 16.5 & 5.7 & 18.9 & 24.3 \\
$\quad$ Rhamnose + fructose & 0.89 & 0.86 & 2.25 & 3.17 \\
$\quad$ Arabinose & 8.44 & 1.85 & 9.97 & 12.49 \\
Xylose & 0.14 & 0.16 & 0.17 & 0.23 \\
$\quad$ Mannose & 0.18 & 0.14 & 0.12 & \\
Galactose & 6.46 & 2.43 & 5.93 & 8.09 \\
Glucose & 0.39 & 0.21 & 0.44 & 0.31 \\
Feruloylester groups & 0.10 & 0.04 & 0.48 & 0.57 \\
Methylester groups & 7.24 & 8.19 & 7.09 & 0.72 \\
Acetylester groups & 5.71 & 4.04 & 7.53 & 0.54 \\
Viscosity-average M.W. & 47700 & 15400 & 42800 & 36400 \\
\hline
\end{tabular}

Numbers are given as $\%(w / w)$, except M.W. 
Table III. Degradation limits of sugar-beet pectins before and after alkaline deesterification.

Pretreatment and

Pectins

mode of degradation

\begin{tabular}{lll}
\hline WSP & OXP
\end{tabular}

\begin{tabular}{l} 
No-pretreatment \\
\hline -elimination \\
pectin lyase \\
polygalacturonase \\
pectate lyase
\end{tabular}

Alkaline deesterification

polygalacturonase

pectate lyase

$7.2^{\text {a) }}$
8.6
1.2
1.0

4.9

4.3

3.7

4.8

4. 6

4.1

1.7

1.3

26.9

23.7

\section{5}

36.7

30.8

29.3

33.4

34.5

31.0

26.4

a) Percentage of galacturonide bonds broken.

Degradation studies. In order to study the distribution of substituents, notably neutral sugar side chains along the rhamnogalacturonan backbone of the pectins, degradation studies were done by $\beta$-elimination (heating at $80^{\circ} \mathrm{C}$ and $\mathrm{pH} 6.8$ for up to $6 \mathrm{~h}$ ) and with various enzymes before and after alkaline demethylation and deacetylation. Table III summarizes the degradation limits obtained with the various methods. $\beta$-Elimination and pectin lyase degradation are known to require methylesterified anhydrogalacturonide residues. The degrees of methylesterification of WSP, OXP, HP and OHP were $76 \%, 60 \%, 62 \%$ and $7,5 \%$, respectively. It is obvious that both break-down mechanisms were strongly promoted with pectins with higher degrees of methylesterification.

The inverse was true for degradation with endopolygalacturonase and pectate lyase. It has been shown by Rexová-Benková et al. (21) that acetylester groups at $\mathrm{C}-2$ and $\mathrm{C}-3$ of anhydrogalacturonic acid residues decrease the extent of degradation by lowering the affinity of endopolygalacturonase for its substrate through blocking of binding sites. In this case a further limitation of the degree of degradation through acetylation is also observed. The degrees of acetylesterification (expressed as moles per 100 moles of anhydrogalacturonide residues) are $31 \%, 16 \%, 35 \%$ and $4 \%$, for WSP, OXP, HP and $\mathrm{OHP}$, respectively. Although the degrees of methylesterification of OXP and HP are quite similar, the degradation limits of these two pectins towards. endopolygalacturonase and pectate lyase are quite different, and probably reflect the difference in acetylesterification. Alkali-soluble pectin (OHP) is largely de-esterified during extraction which explains the high degrees of degradation with polygalacturonase and pectate lyase.

Methylester groups and acetylester groups are both completely removed by alkaline deesterification. That is why the degradation limits for polygalacturonase and pectate lyase are raised to the values shown in Table III. Higher degradation limits for polygalacturonates are reported in literature, both for endopolygalacturonase and endopectate lyase. Rexová-Benková et a1. (21) found $38 \%$, for pectate from citrus pectin degraded by an Aspergillus niger endopolygalacturonase. Rombouts et al. (4) found pectate from apple 
pectin to be degradated to a limit of $35 \%$ by the endopectate lyase used in this study. It is likely that the differences in degradation limits of the alkali-demethoxylated and-deacetylated pectates reflect the number of neutral sugar side chains attached to the pectins. Although WSP has a much higher neutral sugar content than OXP, the alkali-deesterified products are degraded to practically the same extent. This can be explained if indeed the ratio of side chains per unit of chain length in both pectins were simular; those in WSP would then on average be four times as long as those in OXP (compare Tables II and III).

Gel-permeation chromatograms of the digests obtained in various degradation experiments reveal a general trend towards separation of the products into several peaks, in those cases where the degrees of degradation are sufficiently high. The products of sodium-hydroxide deesterified, pectate-lyase degraded pectins are shown in Fig. 2. With WSP, HP and OHP, the peaks near the void volume $\left(\mathrm{K}_{\mathrm{av}}=0-0.5\right)$ represent relatively large fragments, very rich in neutral sugar residues and relatively poor in anhydrogalacturonide residues. In contrast, the peaks in all pectin digests which elute towards the included volume $\left(K_{a v}=1\right)$, are small products (oligogalacturonide fragments) with a very low neutral-sugar content. The oligogalacturonide fragments account for $80 \%, 87 \%, 84 \%$ and $66 \%$ of total anhydrogalacturonide present in WSP, OXP, HP and OHP digests, respectively. Intermediary sized fragments, also relatively rich in neutral sugar residues are present in all four pectin digests $\left(0.7<\mathrm{K}_{\mathrm{av}}<0.9\right)$.

These datav confirm what is known already for certain other pectins, e.g. from apples (20) and cherry fruits (17), that the neutral sugar side chains attached to the rhamnogalacturonan backbone occur in blocks, the so-called "hairy fragments", leaving large parts of the main chain unsubstituted ("smooth fragments").

The size of the hairy fragments of alkali-deesterified pectins can be estimated by determining reducing groups with the NelsonSomogyi method. Those of OHP with $\mathrm{K} \leqq 0.5$. (Fig. 2) for instance, are composed of an average of ten anhydrogalacturonide residues, and up to forty neutral sugar residues (molecular mass about 7500). As these enzyme-resistant fragments will carry a minimum of three or four neutral-sugar side chains, the average size of these would be at least ten to thirteen residues.

A study of the neutral sugar distribution in the large ( $\left.\mathrm{K}_{\mathrm{a}} \leqq 0.5\right)$, intermediate $\left(\mathrm{K}_{\mathrm{av}}=0.7-0.9\right)$ and small $\left(\mathrm{K}_{\mathrm{av}} \geq 0.9\right)$ hairy fragments revealed that arabinose and galactose accumulate in the large and intermediate fragments, rhamnose and xylose in the intermediate and small fragments, and fucose and mannose in the small fragments, but
all sugars are present in all fragments.

Location of acetylester groups. As shown in Table II beet pectins contain $31 \%, 16 \%, 35 \%$ and $4 \%$ acetylester groups expressed as moles per mole of anhydrogalacturonide times $100 \%$, for WSP, OXP, HP and OHP, respectively. There is, however, no solid evidence about the location of these acetylgroups: on the rhamnogalacturonan backbone or rather on the neutral sugar side chains (1). This problem can be studied through enzymatic degradation, and analysis of products.

Fig. 3 shows a gel-permeation chromatogram of a degraded pectin which has undergone sequential treatment with pectin methylesterase 


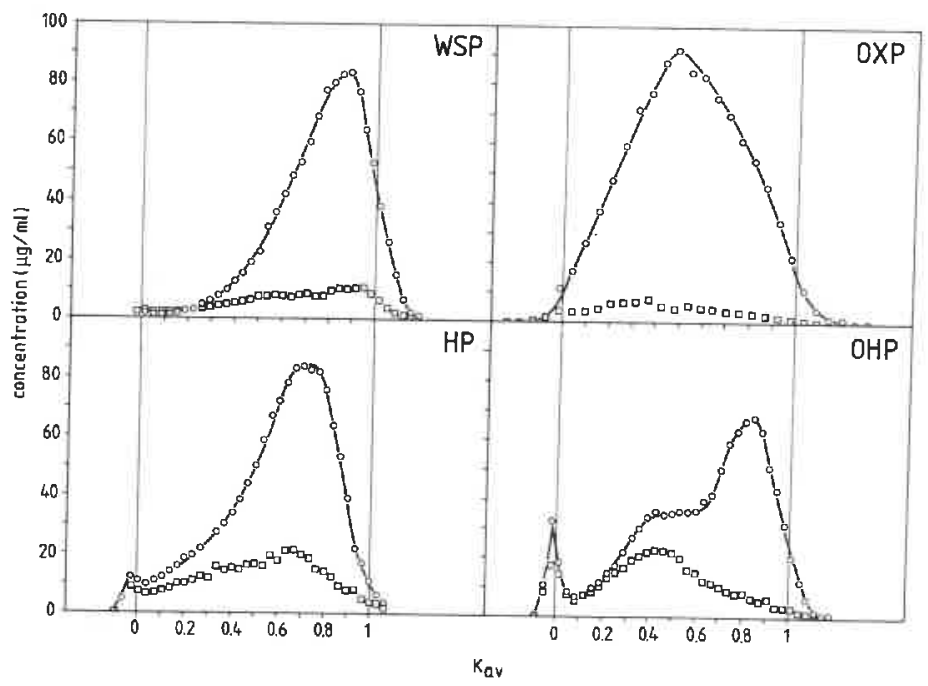

Fig. 1 Gel-permeation chromatograms of purified pectins on Sepharose CL-2B (WSP, HP, OHP) and CL-6B (OXP). Anhydrogalacturonide residues $(0)$, neutral sugar residues ( $\square$ ).

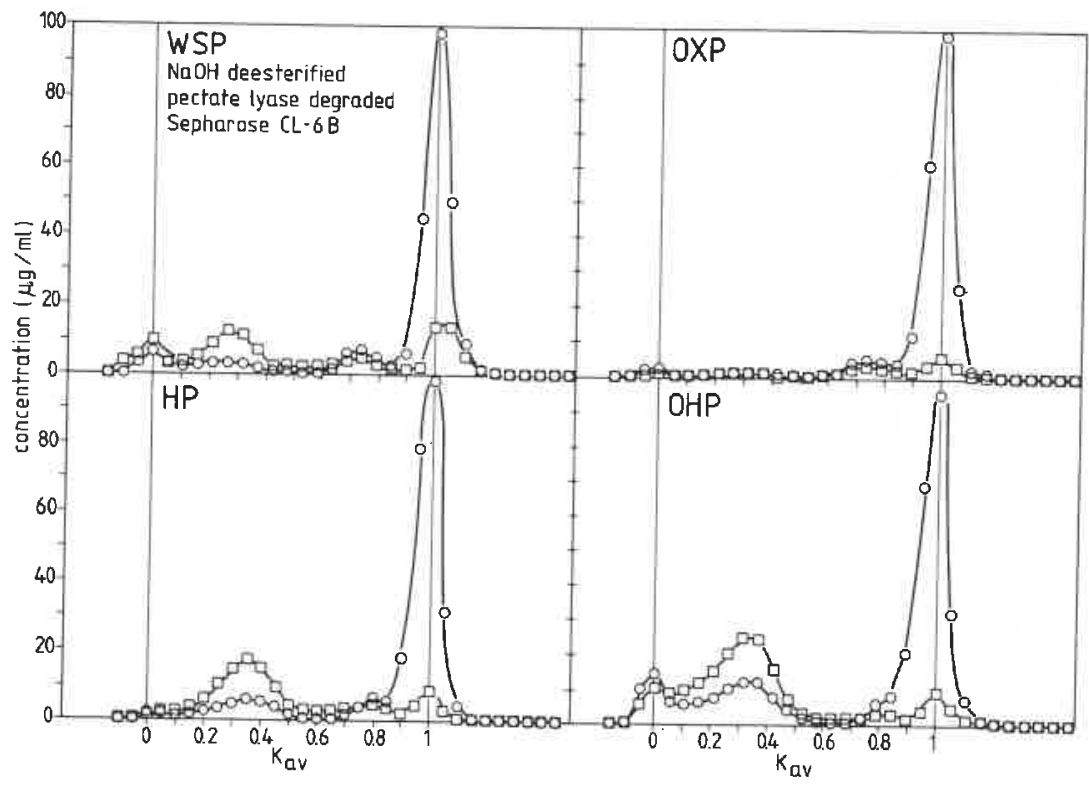

Fig. 2 Gel-permeation chromatograms of sodium-hydroxide deesterified, pectate-lyase degraded sugar-beet pectins. Anhydrogalacturonide residues (0), neutral sugar residues ( $(0)$. 
and polygalacturonase. It appears that the oligogalacturonic acids, which represent $92 \%$ of total anhydrogalacturonide and only $9 \%$ of neutral sugar residues, carry $75 \%$ of the acetylester groups. In addition, exoarabinanase and endogalactanase from Aspergillus niger can liberate some $50 \%$ of the neutral sugar residues, which carry only $8 \%$ of the acetyl groups. The conclusion seems justified therefore that at least 80 to $90 \%$ of the acetyl groups in beet pectin are linked to $\mathrm{C}-2$ and/or $\mathrm{C}-3$ positions of the galacturonide residues.

Presence and location of feruloylester groups. Solutions of sugar beet pectins turn yellow in alkaline medium. There is a bathochromic shift of a double absorption peak at 300 and $325 \mathrm{~nm}$ towards a single peak at $375 \mathrm{~nm}$ which causes this yellow coloration at pH 10 . Also, sugar beet pectins, even when carefully purified as described in "Experimental Methods", react positively in the Folin test. Figure 4 shows an endopectate lyase digest of alkali-deesterified pectin chromatographed on Sepharose CL-6B. The elution profile shows the usual separation pattern of higher molecular mass galacturonides, rich in neutral sugar residues ("hairy fragments") and small oligogalacturonides, with few neutral sugar residues attached. Both fractions react positively in the Folin-test, but, as judged from the elution profile, the Folin-positive material present in the peak around $K_{2 y}=1$ is not bound to the oligogalacturonides. However, chromatography of the "hairy fragments" on DEAESepharose CL-6B confirms that Folin-positive material is bound to these pectin fragments. The absorption spectra at $\mathrm{pH} 4.8$ and 10 , as well as HPTLC-analysis of hydrolysis products of "hairy fragments" have shown that ferulic acid residues are ester-linked to the "hairy fragments" of sugar-beet pectins. These results are in agreement with recent work of Fry (22) who found feruloylester groups linked to araban and galactan side chains of pectin from spinach. This structural feature seems to be restricted to pectin from certain species in the Caryophyllales (Centrospermae) (23); indeed we have not found feruloylester groups in pectins from other plant sources such as potato, apple, citrus, apricots or cherries. With the aid of the molar absorptivity value of 31600 at $\mathrm{pH} 10$, as given by Fry (13), we have determined the feruloylester content of the four pectins. These are quite different (Table I). Acid-soluble and alkali-soluble pectins contain many more feruloylester groups: on average one such group per pectin molecule. It is tempting to presume a relationship between feruloylester content and ease of extraction of the pectins, but this requires further study.

Gelation through oxidative coupling. It has been known for some time that ferulic acid, tyrosine and isotyrosine substituents bound to biopolymers may be involved in the formation of crosslinks in the presence of hydrogen peroxide and peroxidase (24). For instan$c e$, in the case of wheat flour pentosans containing glycoproteins whose carbohydrate moiety carries feruloylester groups, formation of diferulic acid crosslinks results in gel formation. Following up on these observations by Geissmann and Neukom (25) we have succeeded in crosslinking and producing gels from sugar-beet pectin by using peroxidase and hydrogen peroxide according to the reaction shown in Fig. 5 .

Gel formation also occurs with ammonium persulfate, but not with 


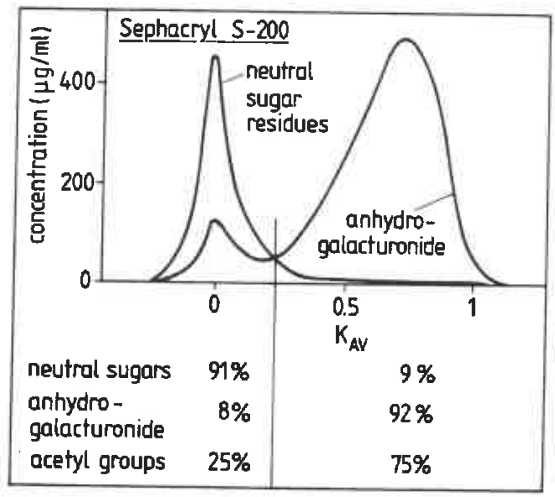

Fig. 3 Gel-permeation chromatogram of acid-soluble sugarbeet pectin degraded with endopolygalacturonase after pectinesterase demethoxylation.

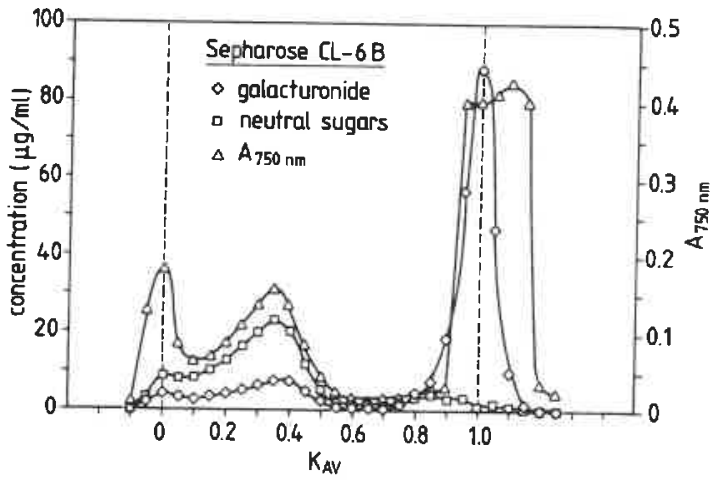

Fig. 4 Gel-permeation chromatogram of an endopectate-lyase digest of alkali-deesterified sugar-beet pectin. 
Table IV. Effect of enzymic crosslinking on intrinsic viscosity and molecular mass of sugar-beet pectin.

\begin{tabular}{lll}
\hline $\begin{array}{l}\text { Concentration of pectin } \\
\text { at crosslinking } \\
(\mathrm{g} / 1)\end{array}$ & $\begin{array}{l}\text { Intrinsic } \\
\text { viscosity } \\
\left(\mathrm{cm}^{3} / \mathrm{g}\right)\end{array}$ & $\begin{array}{l}\text { Molecular } \\
\text { mass }\end{array}$ \\
\hline not crosslinked & 248 & 46000 \\
6 & 435 & 70000 \\
9 & 468 & 73900 \\
15 & 461 & 73000 \\
\hline
\end{tabular}

other oxidation agents, such as permanganate, chlorite, periodate, or hydrogen peroxide alone.

Properties of products. Depending on the concentration of the reactants, the crosslinking reaction may be used to obtain pectins with increased molecular mass or to obtain gels with interesting properties (26). In Table IV the effect of crosslinking with peroxide and peroxidase on apparent molecular mass of the pectin is shown. In this case equimolar amounts of hydrogen peroxide and feruloylester groups were present in the reaction mixtures. High-performance size exclusion chromatograms of such pectins show a growing peak of material with increased molecular mass, as the crosslinking is more intense. Striking increases in reduced viscosity values can also be obtained with persulfate. As with the hydrogen peroxide/peroxidase system, gels are obtained when the pectin concentration is increased above a certain value. Pectin gels obtained by crosslinking with hydrogen peroxide/peroxidase as described in "Experimental Methods" are shown in Fig. 6.

The crosslinked pectin from such gels can be isolated by solvent-drying. The product thus obtained has a remarkable water absorbing capacity. Depending on its form ( $\mathrm{H}$ or $\mathrm{Na}$ ) and the ionic strength of the aqueous solution one gram of the product may absorb 50 to $160 \mathrm{ml}$ of water.

\section{Outlook}

Pectins are traditionally used as gelling and thickening agents in a rather wide range of applications (27). For these purposes pectins from apple pomace and citrus wastes have proven to be superior to those from sugar-beet pulp. In this paper we have reported the presence of feruloylester substituents in beet pectins, and the possibilities for enzymatic and chemical crosslinking through these substituents. This process may lead either to increased apparent molecular mass of soluble pectins, or to gel formation. In addition to the acid-sugar-pectin gel and the calcium-pectate gel, this is a third way of producing gels which is exclusive for pectins from sugar beet. The crosslinked pectins from these gels, isolated by solvent-drying have an extremely high water-absorbing capacity. We feel that this property especially should lead to some new applications e.g. as a cloud stabiliser in drinks, or as water absorbing agent in sanitary products. 


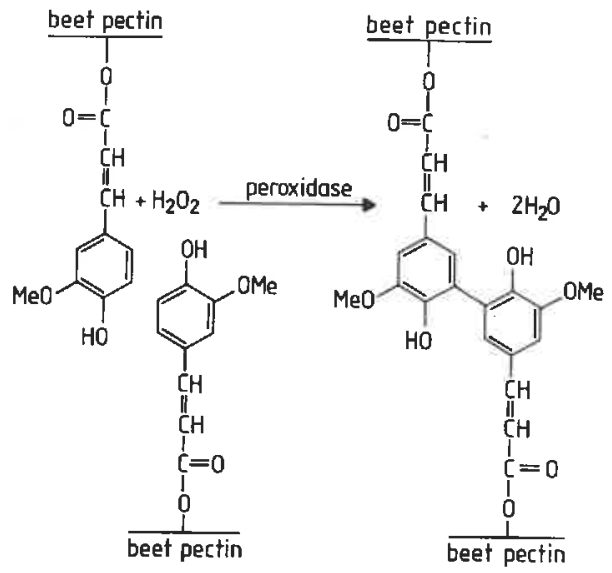

Fig. 5 Crosslinking reaction for sugar-beet pectins (modified from 25).

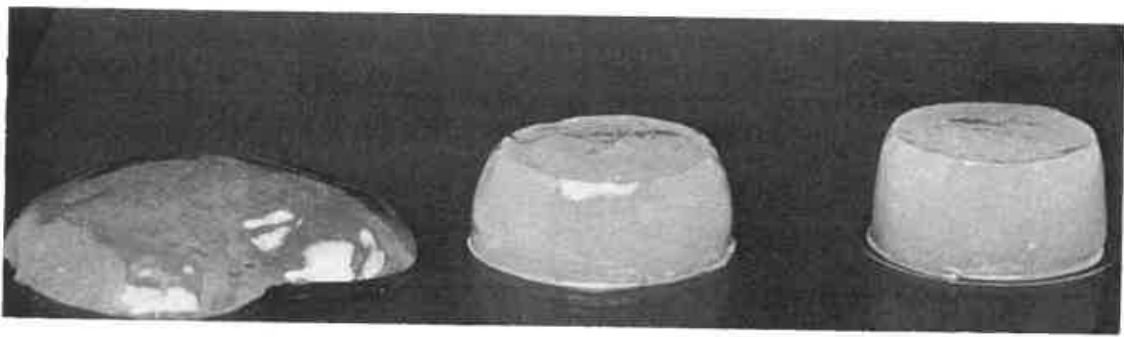

Fig. 6 Gels from acid-soluble sugar-beet pectin, obtained by crosslinking with hydrogen peroxide and peroxidase. The gels are $22 \mathrm{ml}$ each and contain $0.9 \%, 1.8 \%$ and $2.7 \%$ pectin, from left to right. No sugar, acid or calcium salts were used. 


\section{Literature cited}

1 McCready, R.M. J. Am. Soc. Sugar Beet Technol. 1966, 14, 260-70.

2 Pippen, E.L.; McCready, R.M.; Owens, H.S. J. Am. Chem. Soc. $1950,72,813-6$.

3 Thibault, J.F.; Mercier, C. J. Food Biochem. 1978, 2, 379-93.

4 Rombouts, F.M.; Spaansen, C.H.; Visser, J.; Pilnik, W. J. Food Biochem. 1978, 2, 1-22.

5 Van Houdenhoven, F.E.A. Doctoral thesis, Agricultural University, Wageningen, 1975.

6 Baron, A.; Rombouts, F.M.; Drilleau, J.F.; Pilnik, W. Lebensm. -Wiss.u.-Technol. 1980, 13, 330-3.

7 Barbier, M.; Thibault, J.F. Phytochemistry 1982, 21, 111-5.

8 Thibault, J.F. Lebensm.-Wiss.u.-Technol. 1979, 12, 247-51.

9 Tollier, M.T.; Robin, J.P. Ann. Technol. Agric. 1979, 28, 1-15.

10 Albersheim, P.; Nevins, D.T.; English, P.D.; Karr, A. Carbohydr. Res. 1967, 5, 340-5.

11 Wood, P.J.; Siddiqui, I.R. Anal Biochem. 1971, 39, 418-28.

12 Cochrane, G.C. J. Chromatogr. Sci. 1975, 13, 440-7.

13 Fry, S.C. Biochem. J. 1982, 203, 493-504.

14 Swain, T; Hillis, W.E. J. Sci. Food Agric. 1959, 10, 63-8.

15 Owens, H.S.; Lotzkar, H.; Schultz, T.H.; Maclay, W.D. J. Am. Chem. Soc. 1946, 68, 1628-32.

16 Deckers, H.A.; Olieman, C.; Rombouts, F.M.; Pilnik, W. Carbohydr. Polymers (submitted)

17 Thibault, J.F. Phytochemistry 1983, 22, 1567-71.

18 Edstrom, R.D.; Phaff, H.J. J. Biol. Chem. 1964, 239, 2403-8.

19 Spiro, R.G. Meth. Enzymol. 1966, 8, 3-26.

20 De Vries, J.A.; Pilnik, W.; Voragen, A.G.J.; Rombouts, F.M. , This Volume.

21 Rexová-Benková, L. ; Mracková, M.; Luknár, O.; Kohn, R. Col1. Czech. Chem. Comm.. 1977, 42, 3204-13.

22 Fry, S.C. Planta 1983, 157, 111-23.

23 Hartley, R.D.; Harris, P.J. Biochem. Syst. Ecol. 1980, 8, 189-203.

24 Matheis, G.; Whitaker, J.R. J. Food Biochem. 1984, 8, 137-62.

25 Geissmann, T.; Neukom, H. Lebensm.-Wiss.u.-Technol. 1973, 6, 59-62.

26 Rombouts, F.M.; Thibault, J.F.; Mercier, C. French Patent No. $8307208,1983$.

27 Pilnik, W.; Voragen, A.G.J.; Neukom, H.; Nittner, E. In "U11mann's Encyclopedie der Technischen Chemie" Chemie Verlag GmbH: Weinheim, FRG., 1980; Vol. 19, p. 233-63.

RECEIVED December 2, 1985

Reprinted from ACS SYMPOSIUM SERIES No. 310 Chemistry and Function of Pectins

Marshall L. Fishman and Joseph J. Jen, Editors

Copyright $\odot 1986$ by the American Chemical Society

Reprinted by permission of the copyright owner 